\title{
MOTIVAÇÃO E ENSINO DE ESPANHOL NA ESCOLA PÚBLICA PAULISTA: DADOS QUANTITATIVOS E QUALITATIVOS DE UM ESTUDO DE CASO**
}

\author{
MOTIVATION AND SPANISH TEACHING IN SÃO PAULO'S \\ PUBLIC SCHOOLS: QUANTITATIVE AND QUALITATIVE DATA \\ FROM A CASE STUDY
}

\section{Marília Vasques Callegari*}

\section{RESUMO}

O presente artigo tem como objetivo apresentar e discutir os resultados de parte de uma pesquisa empírica levada a cabo em 2008 com alunos de espanhol de um dos Centros de Estudos de Línguas mantido pelo governo estadual de São Paulo. Tínhamos como meta conhecer e mensurar, até onde fosse possível, o nível de motivação dos alunos em sala de aula, assim como as suas principais causas. Uma vez que tais Centros são, no momento, os responsáveis em São Paulo pela aplicação da lei que torna obrigatória a oferta de língua espanhola nas escolas de nível médio do país (no que se refere à escola pública estadual), consideramos pertinente divulgar tais resultados, de forma que as discussões suscitadas por eles possam contribuir para um ensino de línguas mais motivador e, portanto, mais eficiente. A pesquisa, de cunho quantitativo e qualitativo, contou com 161 alunos informantes. Os principais resultados apontaram que i) os estudantes em geral encontram-se motivados durante as aulas de espanhol; ii) a figura do professor, o esforço depreendido, o conteúdo, a autonomia de escolha do idioma estudado e o prazer que têm em aprender a LE foram as principais causas de motivação apresentadas; iii) a falta de conhecimento sobre aspectos culturais da língua alvo foi apontada como uma das principais causas de desmotivação; iv) as atividades descritas como mais motivadoras foram, pela ordem, jogos e brincadeiras, vídeos/ filmes e músicas; v) as atividades consideradas menos motivadoras foram seminário, prova oral/chamada oral e redação.

Palavras-chave: motivação; Centros de Estudos de Línguas; espanhol.

* USP/FE, São Paulo (SP), Brasil. mariliacallegari@usp.br

** O estudo de caso ora apresentado foi realizado como parte de nossa tese de doutorado intitulada "Motivação, ensino e aprendizagem de espanhol: caminhos possíveis. Análise e intervenção num Centro de Estudos de Línguas de São Paulo", defendida em dezembro de 2008, na Faculdade de Educação da Universidade de São Paulo, sob orientação da Profa. Dra. Isabel Gretel María Eres Fernández e subsidiada pelo $\mathrm{CNPq}$. 


\section{ABSTRACT}

The objective of this paper is to present and discuss the results of an empirical survey that took place in 2008 involving students of Spanish from a Center of Foreign Languages Studies (Centros de Estudos de Línguas) sponsored by the State of São Paulo. The goal of the survey was to understand and measure, as far as possible, the degree of student's motivation in the classroom as well as its underlying causes. Taking into account that until now these Centers are responsible to enforce the law that made mandatory the teaching of Spanish for high school students (as far as public schools in the State are concerned), we considered appropriate to publish these results so that the debate engendered by it could contribute to a motivating, and therefore more efficient, foreign language education. The survey, that included quantitative and qualitative information, was based on a sample of 161 students. The results suggested that i) the students were motivated during Spanish classes; ii) the main causes of motivation reported by students were the professor's personality, the effort put in practice, the content, the autonomy in the choice of the language and the pleasure related to learning a foreign language; iii) one of the main causes of demotivation appointed by the survey was the absence of knowledge about cultural aspects related to the language being studied; iv) the activities described as the most motivating were, in this sequence, games and amusing activities, videos/films and songs; v) the activities considered the least motivating were seminars, oral exams/tests and composition.

Keywords: motivation; Center of Foreign Languages Studies; Spanish.

\section{OS CENTROS DE ESTUDOS DE LÍNGUAS: UMA ALTERNATIVA PARA A APRENDIZAGEM DE LÍNGUAS NA ESCOLA PÚBLICA}

Os Centros de Estudos de Línguas do Estado de São Paulo (doravante CEL) foram criados em 1987, com o objetivo de favorecer a "integração latino-americana", conforme explicitado nos documentos oficiais ${ }^{1}$. Inicialmente eram oferecidas nos CEL apenas aulas de língua castelhana, posteriormente foram introduzidos outros idiomas (francês, italiano, alemão, japonês), embora o espanhol continuasse sendo o idioma mais procurado e com mais turmas/alunos.

O objetivo principal dos CEL também sofreu alterações ao longo dos anos, não se restringindo apenas à questão da integração latino-americana. Segundo informações da Coordenadoria de Estudos e Normas Pedagógicas (CENP), órgão da Secretaria da Educação do Estado de São Paulo responsável pelo funcionamento e regulamentação dos CEL,

1. Decreto Estadual n ${ }^{\circ} 27.270$, de 10 de agosto de 1987. 
[...] o objetivo do CEL é propiciar aos alunos diferentes oportunidades de desenvolvimento de novas formas de expressão linguística, enriquecimento curricular e acesso a outras culturas contemporâneas, além de ampliar as possibilidades de inserção no mercado de trabalho. ${ }^{2}$

Em último levantamento feito ${ }^{3}$, contabilizamos no Estado de São Paulo 226 CEL funcionando em 176 cidades. Estima-se que estejam matriculados nos CEL paulistas mais de 50.000 alunos. Para ingressar numa das unidades, o aluno deve estar frequentando cursos regulares ou supletivos na rede estadual. No Ensino Fundamental, são aceitos alunos que cursam a partir do $7^{\circ}$ ano. No Médio, incluemse os alunos dos cursos de educação profissional de nível técnico e do normal de nível médio. O curso, independentemente do idioma escolhido, é dividido em seis estágios, durante três anos. Ao final de três estágios, o aluno já recebe um certificado parcial. Cada estágio tem duração total de 80 horas, distribuídas em quatro aulas semanais. A estrutura física dos CEL em geral é bastante satisfatória, conta com salas ambientes, equipamentos de áudio e vídeo e, em alguns casos, até biblioteca própria.

Os resultados obtidos nos primeiros anos de funcionamento foram muito positivos. Nos últimos anos, no entanto, os CEL passaram por algumas mudanças estruturais que provocaram significativas alterações em seu funcionamento. Em 2001, publicou-se a Resolução $S E n^{0}$ 85, cuja intenção era promover a sua reorganização, "adequando-os à sua finalidade essencial de proporcionar o enriquecimento curricular dos alunos da rede estadual". Dessa forma, várias modificações foram impostas, principalmente no que se refere ao número de alunos dos CEL, à infraestrutura, à contratação de profissionais da área de educação e ao direito dos alunos às vagas oferecidas. Essas diretrizes em muito contribuíram para que a qualidade dos cursos se visse comprometida. As principais consequências que podem ser observadas são:

a) as salas dos estágios iniciais apresentam um número muito grande de alunos, o que dificulta o trabalho do professor e a interação entre os colegas;

b) em uma mesma sala de aula podem estar alunos entre 11 e 18 anos, que apresentam amadurecimento linguístico, intelectual e psicológico muito distintos, o que não é recomendável no processo de ensino e aprendizagem em geral, e tampouco no de línguas estrangeiras;

2. Informações obtidas através do site da CENP (http://cenp.edunet.sp.gov.br/index.htm). Acesso em 11.09.10

3. Maio/12. 
c) os alunos que estiverem cursando algum idioma no CEL e que terminarem o Ensino Médio deverão deixar o curso, ainda que não o tenham concluído ${ }^{4}$;

d) ao exigir-se a saída dos alunos que terminam o Ensino Médio, muitas classes deixam de ter o mínimo de 20 alunos matriculados e são obrigadas a fechar;

e) os alunos das turmas canceladas, ao tentarem se realocar, podem ser matriculados em estágios inferiores ou superiores ao que cursavam, dependendo da disponibilidade de vagas do Centro. Ao serem matriculados em estágios inferiores, os estudantes sentem-se desmotivados ao ver novamente conteúdos que já haviam estudado. No caso contrário, podem sentir-se perdidos e desestimulados ao não conseguirem acompanhar o nível linguístico dos colegas de classe.

Em conversas informais com a coordenação de um dos CEL, fomos informados de que trabalhar com classes tão heterogêneas tem sido uma das principais dificuldades dos professores, que vêm tentando encontrar caminhos que minimizem ou que neutralizem essa situação. Dado que, em um determinado momento, a motivação tanto de alunos como de professores era alta e poderia ser um dos fatores responsáveis pelo sucesso dos cursos, uma das perguntas que esta pesquisa se propunha a responder era se, após as mudanças ocorridas nos últimos anos, o nível motivacional de alunos e professores teria sido afetado negativamente. Em um levantamento realizado por Santos (2007) em cinco Centros de Estudos de Línguas localizados na Grande São Paulo, obtiveram-se os seguintes dados que se relacionam diretamente à nossa pesquisa:

- todos os professores envolvidos na pesquisa acreditam que os CEL têm um papel importante no ensino de LE, por ter qualidade diferenciada e por existirem há vários anos;

- $42 \%$ dos professores e coordenadores consideram a reformulação pela qual passaram os CEL negativa, $36 \%$ a julgam mediana e apenas $21 \%$ a qualificam como positiva;

- o número médio de alunos por sala é de 25,4 e apenas 23\% dos professores consideram esse número adequado;

- $61 \%$ dos alunos consideram que a aprendizagem de inglês na escola onde estudam é ruim. Isso se deve, na opinião dos estudantes, "ao baixo interesse dos alunos em aprender" (62\%), "ao baixo interesse dos professores em ensinar" (45\%) e à má estrutura da escola $(40 \%)$.

Dessa forma, considerando que os CEL se vinculam à escola pública regular e têm uma história de sucesso, ademais de serem os responsáveis, no âmbito público

4. Apesar do texto da Resolução assim determinar, temos notícia de que alguns CEL permitem a continuidade dos estudos de quem conclui o EM. Entretanto, pautamos nossas discussões apenas sobre o que estabelece o texto legal. 
estadual, pela inclusão do ensino de língua espanhola obrigatório, propusemo-nos a conhecer e descrever a opinião de alunos de espanhol de um Centro de Línguas localizado em São Paulo no que se refere à sua motivação.

\section{O NOSSO CAMINHO DE PESQUISA: AS ETAPAS, OS SUJEITOS E OS PROCEDIMENTOS PARA A SUA REALIZAÇÃ $0^{5}$}

O trabalho de cunho empírico foi realizado em um dos Centros de Línguas da cidade de São Paulo. A primeira parte - que ora é descrita - teve como objetivo conhecer a opinião de um número considerável de alunos de espanhol (161), de nove turmas diferentes, e de seus respectivos professores em um dos Centros de Estudos de Línguas - CEL - da cidade de São Paulo, no que tange especificamente à sua motivação durante as aulas de espanhol.

Algumas das perguntas a que nos propusemos responder eram:

a) Os alunos dos CEL encontram-se motivados?

b) Quais as principais causas dessa (des)motivação?

Todos os sujeitos envolvidos nesta primeira etapa da pesquisa preencheram um questionário inicial que nos permitiu responder às perguntas acima apresentadas. A análise dos dados obtidos a partir das respostas dos alunos foi predominantemente de ordem quantitativa. Procuramos detectar, por meio delas, os seguintes aspectos:

- o nível motivacional dos alunos durante as aulas de espanhol no CEL (nível obtido por meio da análise das respostas a uma escala de pontos de 1 a 4 ),

- os pontos mais fracos/fortes apontados pelos alunos (também obtidos por meio das respostas de acordo com a mesma escala);

- as atividades mais/menos motivadoras na opinião dos estudantes (por meio da análise das respostas conforme uma escala de pontos de 1 a 4 ).

Classificamos essa pesquisa como do tipo descritiva e exploratória, uma vez que registramos opiniões sem qualquer tipo de intervenção ou manipulação de variáveis, numa tentativa de diagnosticar a realidade, descrevendo e interpretando os dados fornecidos pelos sujeitos.

5. Ressaltamos que, para testar a adequação dos questionários realizamos previamente um teste-piloto (com 21 alunos e sua respectiva professora) em um dos Centros de Estudo de Línguas da cidade de São Paulo. Dessa forma, para a realização da pesquisa que será descrita a seguir foram feitos ajustes nos instrumentos, de maneira a deixá-los mais claros e eficientes. 


\section{ANÁLISE DOS DADOS}

O instrumento (questionário) que utilizamos nesta fase apresentou-se dividido em quatro partes:

a) dados pessoais;

b) pergunta aberta sobre os motivos que levaram o aluno a querer estudar espanhol,

c) cinquenta e seis afirmações para as quais o aluno deveria marcar se concordava ou discordava, no todo ou em parte, numa escala de 1 a 4 ;

d) relação de 15 atividades que deveriam ser avaliadas pelos alunos, numa escala de 1 a 4 , de acordo com o grau de motivação que suscitam.

Participaram da pesquisa alunos de espanhol, de nove turmas diferentes, de um único CEL da cidade de São Paulo, num total de 161 alunos. A coleta dos dados foi realizada na presença da pesquisadora em todas as turmas, durante o período de aula, de forma que possíveis dúvidas quanto ao preenchimento do questionário foram esclarecidas imediatamente aos alunos. Detalhamos a seguir os principais resultados encontrados.

\section{TABULAÇÃO E ANÁLISE DA PRIMEIRA PARTE DO QUESTIONÁRIO}

A tabulação dos dados da parte inicial do questionário evidenciou um grupo discente predominantemente feminino. Em relação à idade, a maioria está na faixa de 14 a 16 anos, o que demonstra uma certa uniformidade etária. São poucos os alunos que fazem cursos de idiomas fora do CEL, já que a sua clientela, em geral, é formada por alunos de baixa/média renda. No caso dos alunos que fazem um curso de línguas fora do CEL, o idioma estudado é sempre o inglês. Portanto, podemos considerar que nossa pesquisa incide sobre um grupo relativamente homogêneo em termos de faixa etária e experiência na aprendizagem de idiomas estrangeiros.

\section{TABULAÇÃO E ANÁLISE DA SEGUNDA PARTE DO QUESTIONÁRIO}

$\mathrm{Na}$ segunda parte do questionário procuramos identificar os reais motivos que levam um aluno de escola pública a optar pelo idioma espanhol, entre todos os que são oferecidos pelo $\mathrm{CEL}^{6}$, já que o conhecimento dessas razões poderia ser útil

6. O CEL onde realizamos a pesquisa oferece cursos de espanhol, francês, alemão e italiano. 
tanto como um indicativo a mais do nível motivacional dos estudantes quanto para outras investigações que tenham como foco o ensino da língua espanhola nesses contextos. Foi elaborada, portanto, uma pergunta aberta aos participantes: "Por que você decidiu estudar espanhol e não outra língua das oferecidas no CEL?" As respostas foram tabuladas, agrupadas e são descritas a seguir ${ }^{7}$.

Por que você decidiu estudar espanhol e não outra língua das oferecidas no CEL?

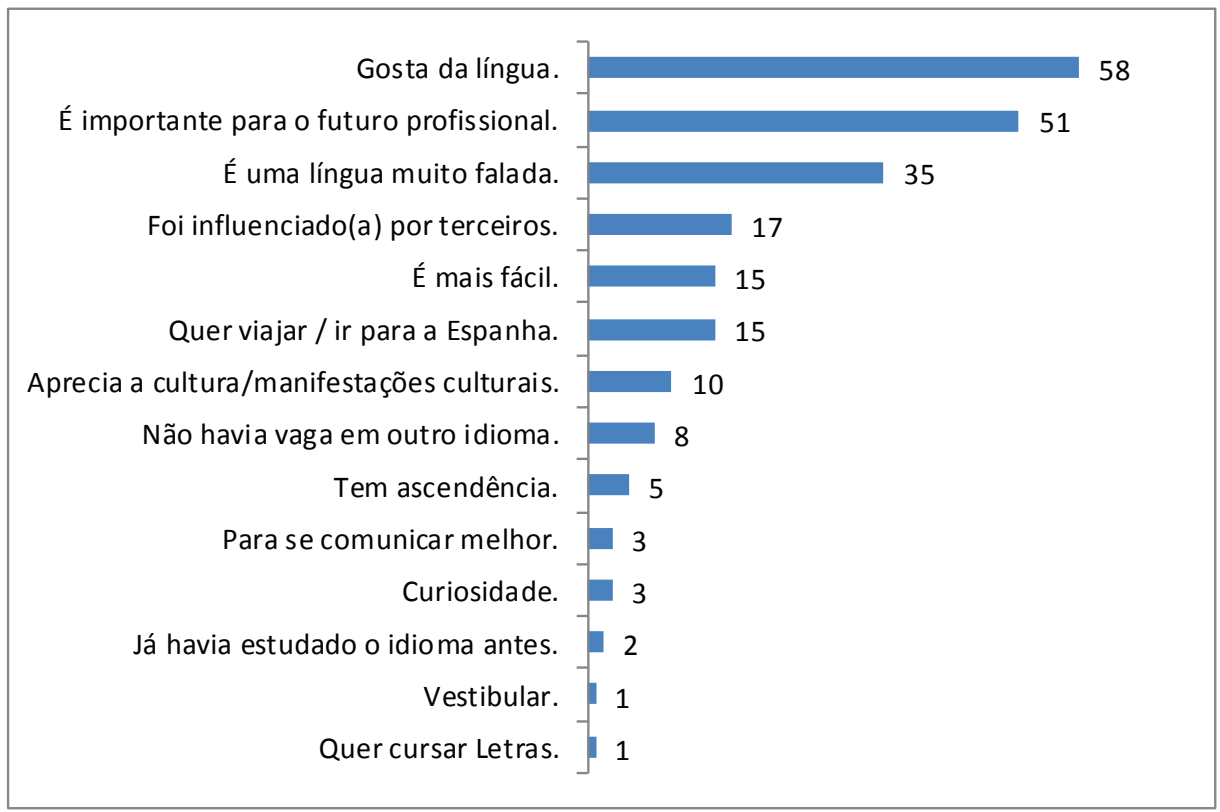

Gráfico 1. Motivos citados pelos alunos participantes da primeira etapa da pesquisa para estudar espanhol no CEL, em números absolutos de menções

Como se pode observar no gráfico 1, as respostas dos alunos foram, no geral, variadas. No entanto, destacou-se, em número de menções, o motivo mais apontado pelos alunos para estudar espanhol: o gosto pela língua. Embora não tenham especificado melhor em suas respostas, supomos que eles se refiram a um conjunto de apreciações para com o idioma, que envolveria sua sonoridade, seu uso, sua cultura, seu prestígio etc. Em segundo lugar em número de menções encontra-

7. Ressaltamos que o número absoluto de respostas (224) é superior ao número de alunos envolvidos (161), já que um mesmo aluno poderia citar mais de uma razão para estudar o idioma. 
se o fato de o conhecimento da língua espanhola ser necessário para o seu futuro profissional. Isso pode ser explicado, talvez, pela faixa etária em que se encontra a maioria dos alunos (14 a 16 anos), momento em que canalizam a sua atenção para a escolha da carreira profissional e em que muitos já começam a buscar o seu primeiro emprego. Além disso, muitas empresas, nacionais e multinacionais, que anteriormente exigiam que os candidatos soubessem se comunicar na língua inglesa, passaram a solicitar também o conhecimento da língua espanhola. Em terceiro lugar, os alunos consideraram o fato de a língua espanhola ser falada por um grande número de pessoas no mundo (segundo dados da UNESCO - 2001, o espanhol ocupa a quarta posição em número de falantes nativos). No entanto, sabe-se que, em importância comercial, o espanhol teve um crescimento considerável nas últimas décadas. No Brasil, especificamente, o estreitamento de relações comerciais - por um lado, com o Mercosul, por outro, por meio do estabelecimento de empresas espanholas em serviços básicos como bancos, empresas de telefonia etc. - fez com que o espanhol passasse a ser não apenas mais conhecido, mas também mais requisitado, mais ensinado e mais aprendido.

É também relevante notar que em quinto lugar está a opinião de que o espanhol é uma língua mais fácil de ser aprendida do que outras. Esse julgamento muitos o fazem, principalmente aqueles que ainda não começaram a estudar o idioma ou os que estão em níveis básicos. Essa crença, há muito conhecida pelos professores e pesquisadores de espanhol, possivelmente deriva da suposta relativa proximidade linguística existente entre o português e o espanhol, as línguasirmãs românicas mais semelhantes. Conforme nos afirma Camorlinga (1997), é indiscutível a facilidade quanto à compreensão ou "uso passivo" do espanhol por falantes do português, já que a maioria das palavras tem uma origem comum. No entanto, essa vantagem inicial nem sempre culmina na apropriação da língua meta, já que justamente as semelhanças podem contribuir para que o aluno faça generalizações equivocadas. Além disso, se, no campo lexical, as semelhanças são frequentes, em campos como a fonologia e a sintaxe, por exemplo, as duas línguas apresentam diferenças consideráveis. Muitas vezes, o aluno só se dará conta delas e da complexidade do outro idioma ao atingir os níveis intermediário/avançado do curso. Como as turmas que participaram da pesquisa cursavam espanhol há cerca de um ano e meio ( $3^{\text {os }}$. estágios), um ano ( $2^{\text {os }}$. estágios) e alguns meses ( $1^{\text {os }}$. estágios) talvez os alunos ainda tenham uma visão estereotipada ou, pelo menos, parcial da aprendizagem do idioma.

Na parte inferior do gráfico, chamou-nos a atenção o número irrisório (1) de alunos que optou pelo estudo de espanhol como preparação para exames 
vestibulares. Esse resultado, no entanto, deve-se, seguramente, ao fato de que pouquíssimas instituições de Ensino Superior paulistas têm, em seus exames seletivos, prova de espanhol. Segundo dados de Kanashiro (2007, p. 57), apenas 5\% das instituições do estado de São Paulo incluem essa opção em seus vestibulares.

\section{CONSTRUÇÃO, TABULAÇÃO E ANÁLISE DA TERCEIRA PARTE DO QUESTIONÁRIO}

Esta terceira parte da pesquisa teve como objetivo inicial inferir o nível motivacional das turmas e identificar os pontos mais problemáticos no que se refere à motivação dos alunos. Secundariamente, por meio dos dados fornecidos pelos alunos de todas as turmas, pudemos conhecer algumas características importantes em relação às aulas de espanhol ministradas no CEL envolvido.

Esta parte do questionário aplicado aos alunos era composta por 56 afirmações. Para cada afirmação os alunos deveriam marcar se concordavam ou discordavam,

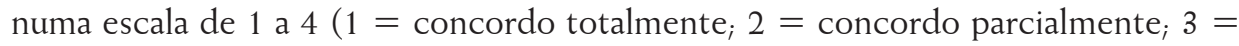
discordo $; 4=$ discordo totalmente).

A construção desse instrumento baseou-se em nosso estudo teórico anterior, sendo que cada uma das afirmações do questionário se relacionava, obrigatoriamente, a um ou mais dos seguintes fatores:

a) a imagem que o aluno tem das comunidades nas quais a LE é falada;

b) o seu conhecimento (ou não) sobre a cultura dos povos que falam essa língua,

c) a visão que tem sobre o prestígio social do idioma no mundo;

d) a utilidade que vislumbra no conhecimento da língua;

e) o desejo de perfeição nas atividades que realiza;

f) sua autoconfiança (engloba fatores como autonomia, autoestima, autoconceito e ansiedade);

g) o conteúdo apresentado em aula;

h) os materiais didáticos utilizados;

i) o método de ensino usado pelo professor;

j) as atividades de aprendizagem que realiza;

k) o sistema e os tipos de avaliação;

1) o número de alunos por sala;

m) a quantidade de horas/aula dispensadas à disciplina;

n) o tipo de autoridade exercido pelo professor;

o) a forma de apresentação das atividades;

p) o feedback proporcionado pelo professor;

q) a necessidade de agradar o professor; 
r) a empatia com relação ao professor;

s) a formação linguística e pedagógica do professor e sua fluência em sala

t) o sistema de normas e recompensas;

u) a coesão do grupo em relação à competitividade, cooperação e individualidade;

v) a motivação do professor;

w) a cobrança por parte da família;

x) o esforço que o aluno está disposto a empregar;

y) suas expectativas em relação ao curso;

z) o apreço que tem pelo idioma.

Para a tabulação desta parte dos dados, definimos que as respostas de número 1 (concordo totalmente) e 2 (concordo parcialmente) seriam consideradas positivas, em oposição às respostas de número 3 (discordo) e 4 (discordo totalmente) que seriam consideradas negativas. Por exemplo, A6: "Espanhol foi a minha primeira opção quando entrei no CEL." Se o aluno marcou a opção 1 (concordo totalmente), significa que está seguro de que cursa o idioma que escolheu; portanto, presume-se motivação. Se respondeu a opção 4 (discordo totalmente), revela que não cursa o idioma escolhido e que estudar espanhol foi algo que ocorreu contrariamente à sua vontade; portanto, presume-se falta de motivação.

A maioria das afirmações seguia essa lógica, exceto as de número A4, A7, A19, A26, A28, A36, A38, A39, A44, A49, A53 e A55, que apresentavam lógica inversa. Por exemplo: A55: "Só aprenderei bem espanhol se fizer um curso à parte, fora do CEL.". Se o aluno marcou a opção 1 (concordo totalmente), está seguro de que o curso do CEL não será suficiente para que aprenda espanhol; portanto, presume-se falta de motivação. Se selecionou a opção 4 (discordo totalmente), revela que confia no curso que está fazendo e em sua qualidade; logo, presume-se motivação. Dessa forma, para analisar as afirmações acima descritas, procedemos à inversão na numeração das respostas, de forma a criar um padrão único. $\mathrm{O}$ intuito de inverter o esquema de pontuação foi tentar evitar que o aluno desse respostas automáticas, "viciando-se" numa mesma opção.

Apenas uma das 56 afirmações não se referia diretamente à motivação dos alunos. Tratava-se da A34: "Eu prefiro fazer os exercícios sozinhos do que em dupla/ grupo." O fato de se preferir atividades em dupla/grupo ou atividades individuais não revela um maior ou menor grau de motivação. No entanto, o resultado obtido com as respostas a essa pergunta poderia revelar a preferência dos alunos sobre a melhor forma de trabalho em sala. Assim, mantivemos a pergunta no questionário, mas não a utilizamos como dado para a análise do nível motivacional das turmas. Após a tabulação das respostas emitidas pelos alunos pudemos comparar os dados 
das nove turmas e classificá-las de acordo com o nível de motivação manifestado. O resultado obtido, em ordem decrescente de motivação, foi:

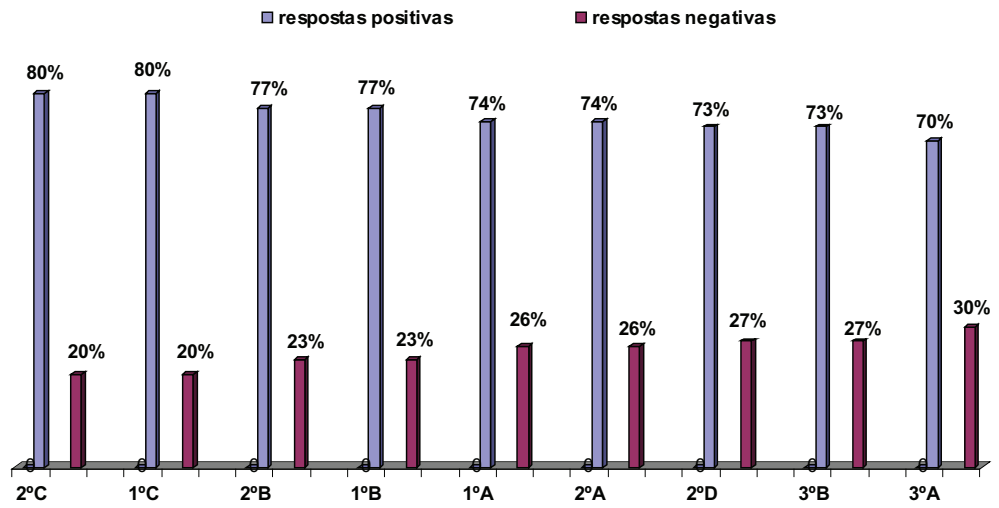

Gráfico 2. Percentual de respostas positivas e negativas de todas as turmas participantes da primeira fase da pesquisa

Conforme pode ser observado, felizmente, nenhuma das nove salas apresentou mais respostas negativas do que positivas. As turmas com maior nível de motivação apresentaram diferença de $10 \%$ em relação à turma com menor nível de motivação.

Procedemos, em seguida, à tabulação dos dados referentes às respostas dadas pelos alunos às 56 afirmações e analisamos os pontos que consideramos mais relevantes.

Primeiramente, procuramos obter um ranking tanto dos pontos mais positivos quanto dos pontos mais negativos, indicados pelos alunos, de acordo com suas respostas às afirmações propostas.

As afirmações que mais receberam avaliações positivas (respostas 1 e 2) foram, em ordem decrescente:

A2: Aprender espanhol é importante para o mercado de trabalho.

A30: Eu me sinto motivado quando o professor me elogia.

A47: Os conteúdos que vemos em sala são importantes.

A13: Eu acredito que vou aprender espanhol.

A46: O/A professor/a sabe bem espanhol.

A52: Se eu estou motivado durante a aula, eu aprendo mais. 
A27: Eu me esforço para ser bem sucedido neste curso.

A8: Estou estudando espanhol porque eu quero.

A43: O/A professor/a fala em espanhol com os alunos na maior parte do tempo.

A9: Eu acho prazeroso aprender espanhol.

A3: Aprender espanhol é importante para viajar.

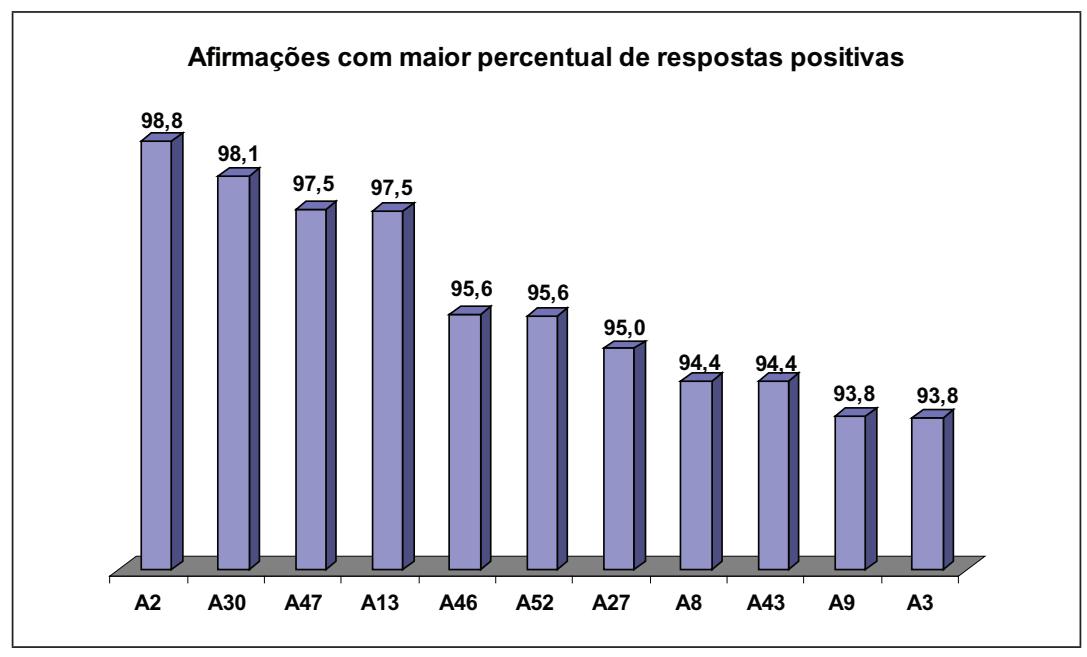

Gráfico 3. Afirmações com maior percentual de respostas positivas (1 e 2), em todas as turmas envolvidas

Esses dados sugerem que os alunos da amostra:

a) realmente consideram a aprendizagem de espanhol importante para o mercado de trabalho, conforme já apontaram em suas respostas à pergunta aberta. Praticamente a totalidade dos alunos (99\%) concorda (total ou parcialmente) com a afirmação. Também acreditam que o conhecimento do espanhol é importante no momento de viajar;

b) sentem-se motivados quando o professor os elogia. O feedback positivo dado pelo professor propicia ao aluno um incremento em sua autoconfiança, em sua autoestima, em seu autoconceito, já que lhe traz a sensação de tarefa bem cumprida, de superação de desafios e de consecução de metas;

c) consideram o conteúdo do curso importante. Como mencionamos, o curso no CEL dura três anos e é dividido em seis estágios semestrais, com conteúdos previamente estabelecidos. A proposta é que os alunos tenham acesso a conteúdo que lhes sirva de base para a comunicação, equilibrando diferentes destrezas (orais e escritas). De acordo com o que pudemos verificar, o conteúdo 
do curso - e de cada estágio - é definido pelo livro didático utilizado. No caso do CEL onde realizamos a pesquisa, usa-se o mesmo livro didático (volume único, destinado ao ensino médio) durante todo o curso, percorrendo-se partes dele em cada estágio. Pelos dados, os alunos aprovam o conteúdo que lhes é oferecido, considerando-o relevante para a sua aprendizagem;

d) apresentam um autoconceito linguístico elevado, já que acreditam que vão aprender espanhol. Esse dado confirma que os alunos dos CEL, em geral, acreditam que é possível aprender espanhol através do curso que realizam, em oposição à crença, amplamente difundida, de que não é possível aprender língua estrangeira na escola regular,

e) têm uma visão positiva da proficiência do professor, já que consideram que ele sabe espanhol e o utiliza na maior parte do tempo durante as aulas. A percepção de que o professor é competente na disciplina que está ministrando é essencial para que os alunos confiem na qualidade do curso. Quanto à utilização do espanhol como língua de comunicação durante as aulas, podemos afirmar que é uma prática habitual e desejável por parte da coordenação do CEL;

f) acreditam que existe uma relação entre motivação e aprendizagem, possivelmente por já terem observado que, em situações nas quais estiveram motivados, a aprendizagem foi facilitada;

g) consideram que dispensam esforço adequado no curso;

h) estudam espanhol por vontade própria e não porque alguém assim o quis, o que ajuda a explicar, em grande medida, os altos valores motivacionais detectados por meio do questionário;

i) consideram a aprendizagem de espanhol prazerosa, agradável, o que facilita sobremaneira o processo de ensino e aprendizagem.

Outros dados que merecem destaque pelo grande número de respostas positivas (tiveram de $85 \%$ a $91,9 \%$ de respostas positivas) são:

a) Os alunos consideram: que o professor explica bem $(91,9 \%)$;

b) que o professor os elogia quando se saem bem $(91,3 \%)$;

c) que se sentem muito motivados durante as aulas de espanhol no CEL $(90,7 \%)$;

d) que os conteúdos vistos em sala são interessantes $(90,6 \%)$;

e) que prestam muita atenção nas aulas $(90,4 \%)$;

f) que admiram os países onde se fala espanhol $(90,1 \%)_{\text {; }}$

g) que o professor é gentil e educado com os alunos (90\%);

h) que gostam de ir à aula de espanhol $(89,4 \%)$,

i) que têm certeza de que em três anos aprenderão a se comunicar em espanhol $(89,4 \%)$

j) que acreditam que podem aprender qualquer LE $(88,8 \%)$,

k) que se sentem mais motivados na aula de espanhol do CEL do que nas aulas de inglês da escola regular $(88,2 \%)$;

1) que o número de alunos por sala é adequado $(87,5 \%)$, 
m) que o curso está atendendo às suas expectativas $(86,9 \%)$;

n) que gostam do livro didático que utilizam $(86,8 \%)$;

o) que o professor parece muito motivado a dar aulas (85\%).

Em contrapartida, as afirmações que mais receberam avaliação negativa (respostas 3 e 4 ) foram:

A17: Eu conheço vários escritores em língua espanhola.

A18: Eu conheço vários pintores de países onde se fala espanhol.

A15: Eu assisto com frequência a filmes nos quais se fala espanhol.

A16: Eu conheço vários cantores que cantam em espanhol.

A19: Eu fico nervoso quando tenho que falar em espanhol em aula ${ }^{8}$.

A49: Quando estou estudando espanhol, eu sempre penso nas provas.

A53: Se o professor promete algum prêmio (como nota ou um chocolate, por exemplo) eu me esforço mais para fazer uma atividade.

A36: Eu tenho vergonha de ler em voz alta na classe.

A54: Sempre que posso eu falo só em espanhol com os colegas de classe.

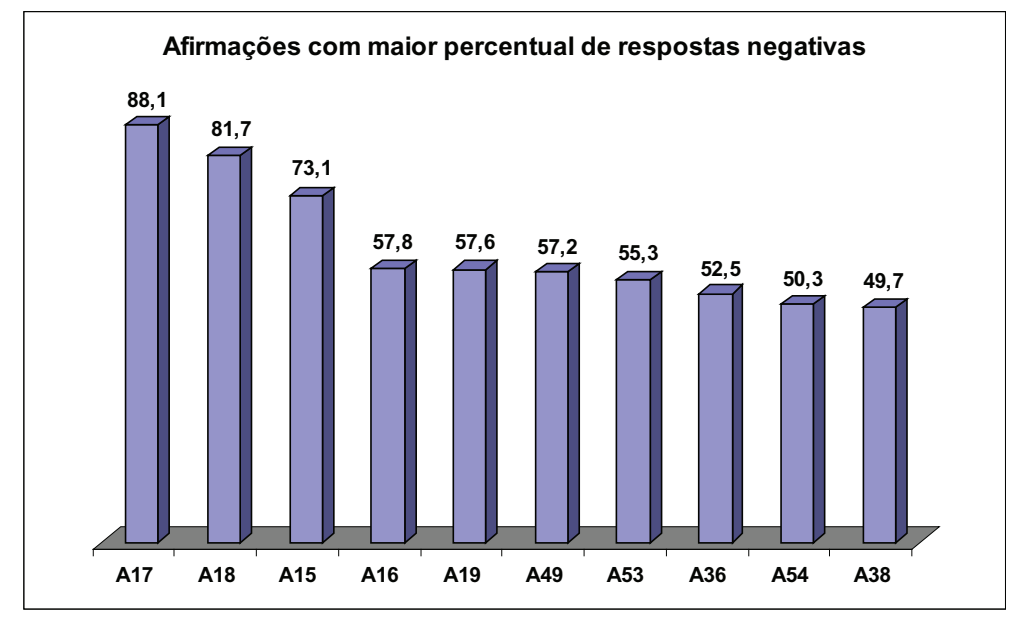

Gráfico 4. Afirmações com maior percentual de respostas negativas (3 e 4), em todas as turmas envolvidas

8. Conforme já relatado, algumas afirmações seguiram lógica inversa da maioria, como é o caso das de número A19, A49, A53 e A36, que aparecem nesta relação. Elas receberam, por parte dos alunos, uma grande parte de respostas 1 e 2, que foram, para efeito de tabulação, mudadas respectivamente para 4 e 3 . 
Os dados obtidos revelam que:

a) as afirmações que se referem ao envolvimento com expressões artísticas (literatura, pintura, música, cinema) tiveram avaliação negativa, denotando pouca exposição dos alunos a determinados aspectos culturais e, portanto, pouco conhecimento e envolvimento;

b) mais da metade dos alunos afirma apresentar sentimentos como nervosismo e vergonha quando precisa falar ou ler em voz alta na sala, o que denota certo grau de ansiedade e timidez;

c) mais da metade dos alunos afirma que ao estudar espanhol tem sempre em mente as provas, o que demonstra que a nota ainda é um dos componentes mais valorizados pelos alunos (e/ou pelos professores) dentro do processo de aprendizagem;

d) metade dos alunos afirma que não tem o hábito de falar em espanhol com os colegas de classe.

Outros dados que também merecem destaque pelo número de respostas negativas que obtiveram (apresentam de $34,4 \%$ a $47,8 \%$ de respostas negativas) são:

a) nas aulas, os alunos usam recursos tecnológicos como TV, vídeo e computador $(47,8 \%)$;

b) o professor devolve as tarefas e avaliações rapidamente $(47,8 \%)$;

c) quando não sabem o significado de uma palavra em espanhol, procuram no livro ou no dicionário antes de perguntar ao professor $(44,7 \%)$;

d) quando o professor dá algum exercício em sala, os alunos se sentem desafiados a fazê-lo $(36,9 \%)$;

e) os alunos se distraem durante as aulas, pensando em outros assuntos alheios à matéria $(34,4 \%)$.

\section{CONSTRUÇÃO, TABULAÇÃO E ANÁLISE DA QUARTA PARTE DO QUESTIONÁRIO}

O nosso objetivo principal, nesta etapa da pesquisa, era verificar que atividades são consideradas mais/menos motivadoras pelos alunos em sala de aula. Esta parte do questionário continha a relação de quinze tipos de atividades, comumente realizadas em aulas de língua estrangeira. Os alunos foram solicitados a marcar o grau de motivação que cada uma delas lhes suscitava, por meio das seguintes opções: "me motiva muito", "me motiva", "me motiva pouco", "não me motiva nada". Para efeitos de tabulação, atribuímos os seguintes valores a cada uma 
dessas opções: "me motiva muito" $=1$; "me motiva" $=2 ;$ "me motiva pouco" $=3$ e "não me motiva nada" $=4$.

Quanto mais próxima de 1 está a atividade, mais ela foi considerada motivadora por parte dos alunos. No outro extremo, quanto mais próxima de 4, menos motivadora na opinião dos estudantes. Os resultados obtidos podem ser visualizados no gráfico a seguir:

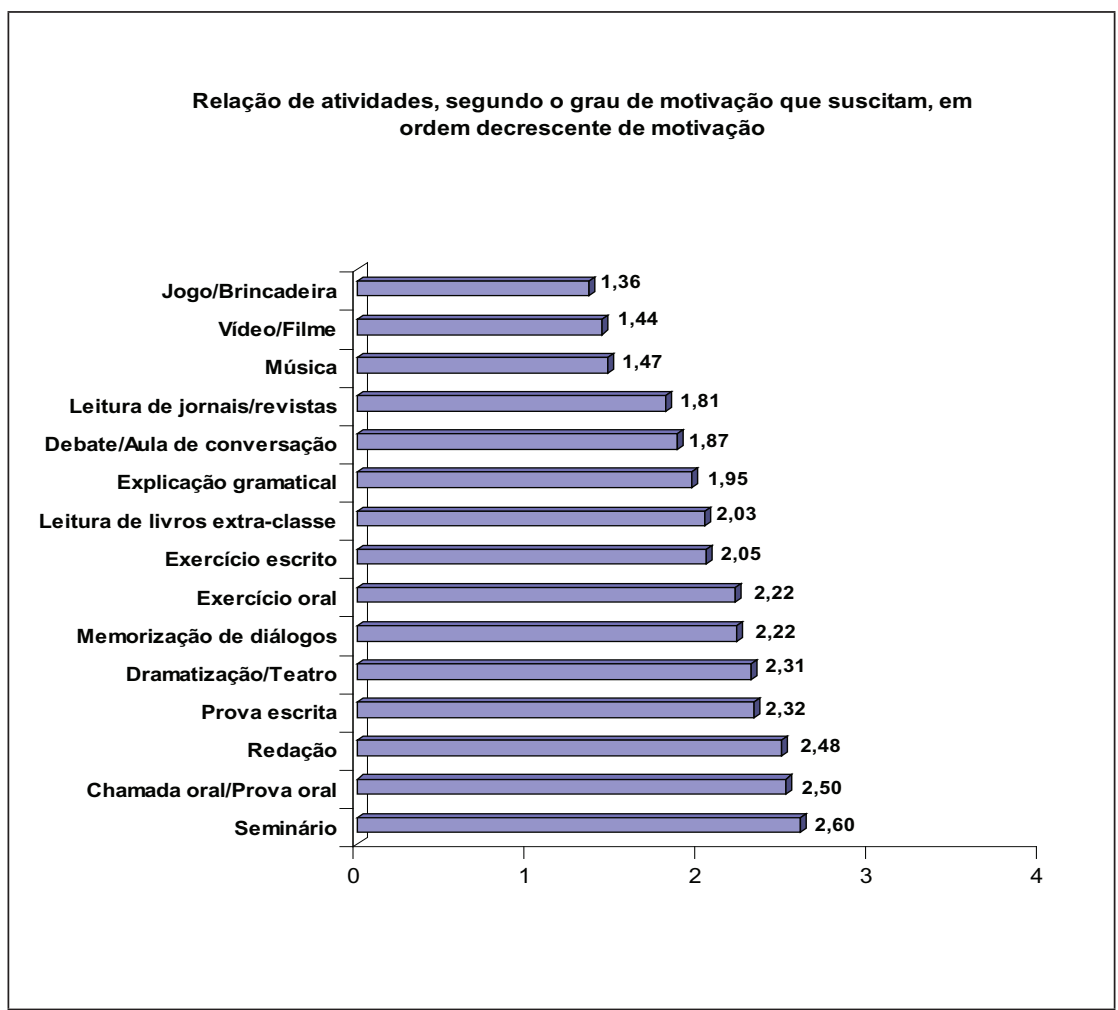

Gráfico 5. Atividades segundo o grau de motivação que suscitam, em ordem decrescente de motivação - alunos envolvidos na primeira etapa da pesquisa

Os dados apresentados revelam que:

a) a primeira atividade em ordem de preferência dos alunos é "jogos e brincadeiras", item que havia ficado em segundo lugar em nossos dados no Mestrado (2004). Conforme apontado nesse trabalho, o jogo e as atividades lúdicas em geral geram 
nos alunos uma motivação diferente da encontrada em outras atividades, já que, conforme afirma Huizinga (1996, p. 10) “o jogo não é 'vida corrente’ nem 'vida real'." O jogo suspende, por alguns instantes, a realidade e introduz um "mundo de faz-de-conta", denominado por Winnicott (1975) de "espaço transicional" ou "espaço da ilusão". Para esse psiquiatra inglês, "é no brincar, talvez apenas no brincar, que a criança ou o adulto fruem sua liberdade de criação." (1975, p. 79)

Os professores, por sua vez, também tendem a considerar o jogo como uma prática motivadora em aula, já que a sua utilização parece trazer benefícios facilmente observáveis, como os que nos apontam Zipman et al. (2001, p. 213): relajan al alumno; lo desinbiben; lo motivan; favorecen la práctica del contenido de clase de una forma lúdica; ayudan en la integración del grupo; facilitan la comunicación real; favorecen la participación activa, favorecen la interiorización ${ }^{9}$.

b) a opção "vídeo/filmes" obteve o segundo lugar na preferência da maioria dos alunos pesquisados, diferentemente do resultado obtido em nossa dissertação de Mestrado (2004). quando aparecia apenas em $13^{\circ}$ lugar de um total de 14 opções. Nos últimos anos, é possível observar um crescente interesse por filmes originalmente falados em espanhol e a facilidade de levá-los à sala de aula pode ter contribuído para esse resultado. No entanto, assim como apontado no item anterior, a afirmação A15 "Eu assisto com frequência a filmes nos quais se fala espanhol" teve um número baixíssimo de avaliações positivas.

c) a utilização de músicas foi também uma atividade bem avaliada pelos alunos em aulas de espanhol, embora nesta pesquisa apareça em terceiro lugar e não em primeiro, como em nossa dissertação de Mestrado (2004). Neste caso especificamente, o que chama a atenção é o fato de que a afirmação A16, "Eu conheço vários cantores hispânicos", teve um grande número de avaliações negativas.

d) "debates/conversação" aparece em quarto lugar na preferência dos alunos pesquisados. É importante ressaltar que essas atividades enfocam a expressão oral de forma contextualizada, diferentemente de "memorização de diálogos" e "prova oral" que não obtiveram o mesmo número de respostas positivas, o que indica que os alunos se sentem mais motivados nas atividades em que podem se valer de outras habilidades, mais criativas, além da memória. Outro dado relevante a considerar é que, embora "prova oral/chamada oral" e "seminário" também sejam atividades que enfatizam a oralidade, essas obtiveram os piores resultados na pesquisa. Isso muito possivelmente se deve ao fator "avaliação" presente nessas práticas, que pode gerar uma ansiedade e um temor maior do que em atividades orais que não tenham relação direta com a nota ${ }^{10}$.

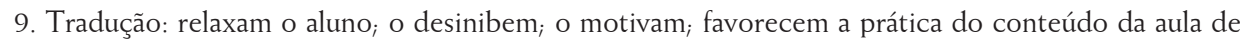
forma lúdica, auxiliam a integração do grupo $;$ facilitam a comunicação real ${ }_{i}$ favorecem a participação ativa, favorecem a interiorização. 
e) prova escrita e redação também foram atividades mal avaliadas pelos alunos, confirmando os dados obtidos anteriormente em nossa dissertação de Mestrado (2004), quando as piores avaliações foram dadas à "prova oral/chamada oral", "prova escrita" e "redação", nessa ordem. No caso de prova escrita, mais uma vez fica claro que os alunos não se sentem confortáveis em situações de explícita avaliação. Quanto à redação, esta exige um preparo atento e minucioso, que envolve consultas a outros materiais (como o dicionário ou um glossário, por exemplo) e levam tempo para que o resultado seja satisfatório, fatores que talvez expliquem porque não são atividades agradáveis aos alunos.

\section{CONCLUSÕES}

Concluindo esta parte de nossa análise, podemos afirmar que:

a) se tratava de salas com um número de alunos adequado, tanto em nossa concepção quanto do ponto de vista dos alunos, já que a afirmação A10 "Eu acho que o número de alunos que temos em sala é adequado" teve $87,5 \%$ de respostas positivas;

b) as salas apresentavam nível motivacional alto, já que a média geral de respostas positivas foi de $75,3 \%$;

c) no que se refere às afirmações propostas, os pontos mais fortes recaíram em várias instâncias (especialmente na figura do professor, no esforço depreendido, no conteúdo, na autonomia de escolha do idioma estudado, no prazer que têm em aprender a LE);

d) os pontos mais fracos recaíram especialmente no conhecimento dos alunos sobre aspectos culturais do mundo hispânico, nas recompensas externas às atividades e em sentimentos pouco agradáveis gerados pela exposição frente aos demais.

e) as atividades consideradas mais motivadoras na opinião dos alunos foram jogos/brincadeiras, vídeos/filmes e músicas, nessa ordem.

f) as atividades consideradas menos motivadoras foram seminário, prova oral/ chamada oral e redação.

10. Para informações mais detalhadas e específicas sobre produção oral em aulas de LE, consultar: MORENO FERNÁNDEZ, F. Producción, expresión e interacción oral. Madrid: Arco Libros, 2002. $91 \mathrm{p}$.

SÁNCHEZ LOBATO et al. El desarrollo de la expresión oral en el aula de E/LE. Revista Carabela, 47. Madrid: SGEL, 2000.

VÁZQUEZ, G. La destreza oral. Conversar, exponer, argumentar. Madrid: Edelsa, 2000. 138p. 


\section{REFERÊNCIAS BIBLIOGRÁFICAS}

CALLEGARI, M. O. V. (2004) Saborear para saber: diferentes olbares sobre a motivação em sala de aula - um estudo com alunos e professores de espanbol do Ensino Médio. Dissertação (Mestrado em Educação) - Faculdade de Educação, Universidade de São Paulo, São Paulo.

CAMORLINGA, R. (1997) A distância da proximidade. A dificuldade de aprender uma língua fácil. Revista Intercambio. vol. VI, São Paulo. Disponível em: < http://www2.lael. pucsp.br/ tony/intercambio anteriores/06index.htm $>$ (Acesso: 17.10.08)

HUIZINGA, J. (1996) Homo Ludens: O Jogo como Elemento da Cultura. 4 ed. Tradução João Paulo Monteiro. São Paulo: Perspectiva.

KANASHIRO, D. S .K. (2007) Do ensino médio ao superior: que ponte os une? Um estudo de provas de vestibular de língua espanbola. Dissertação (Mestrado em Educação) - Faculdade de Educação, Universidade de São Paulo, São Paulo.

SANTOS, J. J. (2007) Centros de Estudos de Línguas (CELs) do Estado de São Paulo: uma longa experiência no ensino de Espanhol Língua Estrangeira (ELE). 2007. Relatório (Iniciação Científica) - Faculdade de Educação, Universidade de São Paulo.

SÃO PAULO (1987) Decreto Estadual n 27.270, de 10 de agosto.

UNESCO (2001). Informe mundial sobre la cultura 2000-2001: diversidad cultural, conflicto y pluralismo. Madrid: Mundi-Prens, Ediciones UNESCO.

WINNICOTT, D. W. (1975) O brincar e a realidade. Trad. José O. Aguiar e Vanede Nobre. Rio de Janeiro: Imago Editora.

ZIPMAN et al. (2001) Parchis, Scrabble, Oca, 1000 nombres... proceso de aprendizaje creativo y ameno, ċvamos a jugar? In: VIII Seminario de Dificultades específicas de la enseñanza del español a lusohablantes: elaboración de materiales para la clase de español, 2000. Actas... Brasília: Embajada de España en Brasil, Consejería de Educación, Ministerio de Educación, Cultura y Deporte de España, p. 210-244.

Recebido: 14/09/2010

Aceito: 03/03/2012 